\title{
EVALUASI KESESUAIAN LAHAN UNTUK PENGEMBANGAN TANAMAN JERUK (Citrus, sp) DI DESA JAMBO LABU KECAMATAN BIREM BAYEUN KABUPATEN ACEH TIMUR
}

\author{
Rosmaiti $^{1}$, Iwan Saputra ${ }^{2}$, Yusnawati ${ }^{3}$ \\ 1Dosen Program Studi Agroteknologi, Fakultas Pertanian Universitas Samudra \\ ${ }_{2}$ Dosen Program Studi Agroteknologi, Fakultas Pertanian Universitas Samudra \\ 2Alumni Program Studi Agroteknologi, Fakultas Pertanian Universitas Samudra Alamat. \\ Jln. Meurandeh, Kec. Langsa Lama, Kota Langsa, Aceh, Indonesia Telp. (0641) 426487 \\ Email : rosmaitimp@unsam.ac.id
}

\begin{abstract}
ABSTRAK
Tujuan dari penelitian ini untuk menetapkan karakteristik dan kesesuaian lahan, faktor-faktor pembatas lahan terhadap kesesuaian lahan dan klasifikasi kesesuaian lahan jeruk untuk tanaman jeruk di Desa Jambo Labu Kecamatan Birem Bayeun Kabupaten Aceh Timur. Penelitian ini menggunakan metode survei deskriptif yaitu dengan survey lahan dan pengambilan sampel tanah di lapangan serta hasil analisis sampel tanah di laboratorium. Titik pengamatan dan pengambilan sampel tanah dibentuk berdasarkan satuan peta lahan hasil overlay (tumpang susun) antara peta jenis tanah, peta lereng, dan peta penggunaan lahan. Hasil penelitian menunjukkan bahwa lokasi penelitian sesuai untuk pengembangan tanaman jeruk walaupun dapat terlihat media perakaran, retensi hara, hara tersedia dan tingkat bahaya erosi sebagai faktor pembatas/S3 (sesuai marginal). Berdasarkan hasil evaluasi kesesuaian lahan dilokasi penelitian menunjukan bahwa lahan tersebut sesuai untuk pengembangan tanaman jeruk walaupun dapat terlihat media perakaran, retensi hara, hara tersedia dan tingkat bahaya erosi sebagai faktor pembatas/S3 (sesuai marginal) dapat diperbaiki menjadi S1 (sangat sesuai). Karakteristik lahan S3 untuk pengembangan tanaman jeruk di Desa Jambo Labu Kecamatan Birem Bayeun dapat memberikan input perbaikan untuk kesesuian lahan agar dapat dinaikan kelas kesesuaiannya menjadi S1 (sangat sesuai). Upaya perbaikan media perakaran dengan pembuatan saluran drainase, retensi hara ( $\mathrm{pH}$ tanah) dengan pengapuran, hara tersedia (total $\mathrm{N}$ dan $\mathrm{P}_{2} \mathrm{O}_{5}$ ) dengan pemberian pupuk yang mengandung unsur nitrogen/pupuk organik dan pupuk yang mengandung unsur fosfor dan tingkat bahaya erosi (bahaya erosi dan lereng) $8-15 \%$ dengan cara konservasi vegetatif. Hasil penelitian ini dapat dilanjutkan dengan percobaan dilapangan dengan melakukan penanaman jeruk dengan perlakuan penambahan pupuk yang mengandung unsur $P$ dan $N$, penanaman kacang hias (Arachis pintoi) pada lereng $8-15 \%$.
\end{abstract}

Kata kunci : jeruk, evaluasi lahan, Aceh Timur

\begin{abstract}
This study aims to determine the characteristics and suitability of land, limiting factors of land to land suitability and suitability classification of citrus land for citrus plants in Jambo Labu Village, Birem Bayeun District, East Aceh Regency. This research uses descriptive methods, namely land survey and soil sampling in the field and analysis of soil samples in the laboratory. The point of observation and sampling of land is formed based on the units of the land map resulting from overlays (overlapping intervals) between the soil type map, slope map, and land use map. The results showed that in the study area it was suitable for the development of citrus plants although it could be seen rooting media, nutrient retention, available nutrients and erosion hazard levels as limiting factors / S3 (according to marginal). Based on the results of evaluation of land suitability on the location of the study showed that the land is suitable for the development of citrus plants although it can be seen rooting media, nutrient retention, nutrient availability and erosion hazard level as a limiting factor / S3 (according to marginal) can be improved to S1 (very suitable). The land characteristics of S3 for
\end{abstract}


the development of citrus plants in Jambo Labu Village, Birem Bayeun Sub-district can provide improved input for land suitability so that the suitability class can be increased to S1 (very suitable). Efforts to improve root media by making drainage canals, nutrient retention (soil pH) with calcification, available nutrients (total $N$ and P2O5) by providing fertilizers containing nitrogen / organic fertilizers and fertilizers containing phosphorus and erosion hazard levels (erosion hazard and slope) $8-15 \%$ by means of vegetative conservation. The results of this study can be continued with experiments in the field by planting citrus with the addition of fertilizer containing $P$ and $N$ elements, planting ornamental beans (Arachis pintoi) on the slopes of 8-15\%.

Keywords : citrus, land evaluation, East Aceh

Diterima: 17 Maret 2019, disetujui 6 Mei 2019

\section{PENDAHULUAN}

Jeruk merupakan salah satu komoditi buah-buahan yang mempunyai peranan penting di pasaran dunia. Saat ini Indonesia termasuk negara pengimpor jeruk terbesar kedua di ASEAN setelah Malaysia. Oleh karena itu, pemacuan produksi jeruk nasional akan memiliki urgensi penting karena disamping untuk meningkatkan pendapatan masyarakat, kesempatan kerja, konsumsi buah dan juga meningkatkan devisa ekspor nasional. Impor buah jeruk segar yang terus meningkat, mengindikasikan adanya segmen pasar (konsumen) tertentu yang menghendaki jenis dan mutu buah jeruk prima yang belum bisa dipenuhi produsen dalam negeri (Kementan, 2016).

Data produksi jeruk di Indonesia pada periode 1980-2014 meningkat dengan rata-rata pertumbuhan sebesar $10,34 \%$ per tahun. Pada periode 1980-2009 rata-rata pertumbuhan produksi jeruk sebesar $12,38 \%$ per tahun namun selama kurun waktu 20102014 rata-rata produksi jeruk menurun sebesar $1,49 \%$ per tahun. Secara umum terjadi peningkatan produksi jeruk di Indonesia dari 311.014 ton pada tahun 1980 menjadi 1,93 juta ton pada tahun 2014 dimana produksi jeruk tertinggi dicapai pada tahun 2007 yaitu sebesar 2,63 juta ton atau naik 2,35\% terhadap tahun 2006 (Pusat data dan Sistem Informasi Pertanian, 2015).

Data produksi buah jeruk di Kabupaten Aceh Timurtertinggi pada tahun 2015 mencapai 1.114,15 ton, sedangkan produksi terendah pada tahun 2016 mencapai
597,20 ton. Pada Kabupaten Aceh Timur terdapat beberapa kecamatan yang mempunyai tanaman belum menghasilkan, tanaman produktif, tanaman produksi menghasilkan dan produksi (ton/ha) Tanaman Jeruk disajikan pada Tabel 1.

Dari hasil wawancara langsung di lapangan produksi tanamanjeruk Tahun 2017 diDesa Jambo Labu Kecamatan Birem Bayeun Kabupaten Aceh Timur mencapai 35 ton dari 4 petani yang mempunyai lahan jeruk seluas 13 Ha. Desa Jambo Labu merupakan daerah penghasil salah satu tanaman perkebunan yaitutanaman jeruk. Informasi kelas kesesuaian lahan untuk tanaman jeruk di desa ini masih belum ada. Oleh karena itu, penelitian ini perlu dilakukan guna untuk mengetahui kesesuaian lahan yang sesuai untuk tanaman jeruk, mengingat daerah ini memiliki lahan yang luas dan berpotensi untuk pengembangan tanaman jeruk. Dengan adanya informasi kelas kesesuaian lahan untuk pengembangan komoditi jeruk diharapkan dapat dilakukan alternatif yang tepat guna meningkatkan produksi dan kesejahteraan masyarakat di Desa Jambo Labu Kecamatan Birem Bayeun Kabupaten Aceh Timur.

Menurut Sitorus (2004), kesesuaian lahan adalah penggambaran tingkat kecocokkan sebidang lahan untuk suatu penggunaan tertentu. Kelas kesesuaian suatu areal dapat berbeda tergantung dari tipe penggunaan lahan yang sedang dipertimbangkan. Hal ini dikarenakan lahan 
yang digunakan untuk budidaya tanaman jeruk di Desa Jambo Labu mempunyai tingkat kesesuaian lahan yang belum optimal, salah satu permasalahan dalam menyetarakan produktivitas tanaman jeruk antar petani di Desa Jambo Labu adalah belum adanya kegiatan evaluasi mengenai kesesuaian lahan terhadap tanaman jeruk.

Tabel 1. Rata - rata Produksi Tanaman Jeruk di Kabupaten Aceh Timur.

\begin{tabular}{clcccc}
\hline No & Kecamatan & $\begin{array}{c}\text { Tanaman } \\
\text { Belum } \\
\text { Menghasilkan } \\
\text { (Batang) }\end{array}$ & $\begin{array}{c}\text { Tanaman } \\
\text { Produktif } \\
\text { (Batang) }\end{array}$ & $\begin{array}{c}\text { Tanaman } \\
\text { Produksi } \\
\text { Menghasilkan } \\
\text { (Batang) }\end{array}$ & $\begin{array}{c}\text { Produksi } \\
\text { (Ton/Ha) }\end{array}$ \\
\hline 1 & Peunaron & 0 & 238 & 238 & 40,50 \\
2 & Birem Bayeun & 30 & 150 & 150 & 50,20 \\
3 & Sungai Raya & 0 & 8 & 8 & 1,60 \\
4 & Peureulak & 0 & 185 & 185 & 22,80 \\
5 & Peureulak Barat & 0 & 20 & 20 & 4,20 \\
6 & Peudawa & 0 & 23 & 200 & 1,10 \\
7 & Bandar Alam & 0 & 281 & 210 & 23,00 \\
8 & Idi Tunong & 0 & 210 & 53,30 \\
9 & Darul Falah & 0 & 50 & 830 & 9,40 \\
10 & Pante Bidari & 0 & 860 & 1.839 & 61,50 \\
11 & Simpang Ulim & 0 & 1.839 & 1670 & 169,00 \\
12 & Madat & 0 & 1.900 & 5.423 & 150,60 \\
\hline
\end{tabular}

Sumber : BPS Aceh Timur, 2017

Menurut Ritung dkk (2007), konsep evaluasi lahan adalah suatu proses penilaian sumberdaya lahan untuk tujuan tertentu dengan suatu pendekatan atau cara yang sudah teruji. Hasil evaluasi lahan akan memberikan informasi dan arahan penggunaan lahan sesuai dengan keperluan. Sedangkan konsep kesesuaian lahan adalah tingkat kecocokan sebidang lahan untuk penggunaan tertentu. Kesesuaian lahan tersebut dapat dinilai untuk kondisi saat ini (kesesuaian lahan aktual) atau setelah diadakan perbaikan (kesesuaian lahan potensial).

Hasil yang maksimalakan diperoleh dengan cara analisis kesesuain lahan untuk pengembangan tanaman jeruk. Tingkat kesesuaian lahan dapat diketahui dengan cara membandingkan antara syarat tumbuh tanaman jeruk dengan karakteristik lahan pada setiap satuan peta lahan sehingga dapat diketahui faktor pembatas yang mempengaruhi kelas kesesuaian lahan tersebut. Usaha khusus dapat dilakukan menangani faktor pembatas kelas kesesuaian lahan dengan tujuan agar memperoleh tingkat kesesuaian lahan yang lebih baik yang akan berdampak pada hasil produksi jeruk pada lahan yang bersangkutan.
Berdasarkan uraian diatas maka penulis ingin melakukan penelitian tentang "Evaluasi Kesesuian Lahan untuk Pengembangan Tanaman Jeruk (Citrus, sp.) di Desa Jambo Labu Kecamatan Birem Bayeun Kabupaten Aceh Timur". TujuanPenelitian adalah menetapkan karakteristik dan kesesuaian lahan untuk tanaman jeruk di Desa Jambo Labu, Kecamatan Birem Bayeun Kabupaten Aceh Timur, menetapkan faktor-faktor pembatas lahan terhadap kesesuaian lahan untuk tanaman jeruk di Desa Jambo LabuKecamatan Birem Bayeun Kabupaten Aceh Timur, menetapkan klasifikasi kesesuaian lahan untuk pengembangan tanaman jeruk di Desa Jambo Labu Kecamatan Birem Bayeun Kabupaten Aceh Timur.

\section{METODE PENELITIAN}

Penelitian dilakukan di Desa Jambo Labu Kecamatan Birem Bayeun Kabupaten Aceh Timur. Letak geografis lokasi penelitian yaitu terletak pada posisi $4^{\circ} 18^{\prime} 0$ " 
- 4o 30' 0" Lintang Utara dan $97^{\circ} 45^{\prime} 0$ " 97o 55' 30" Bujur Timur. Waktu penelitian dilakukan selama 2 bulan, yang di mulai dari bulan September- November 2018. Analisis sampel tanah dilaksanakan di Laboratorium Penelitian Tanah dan Tanaman Fakultas Pertanian Universitas Syiah Kuala Banda Aceh.

Bahan yang digunakan pada penelitian ini adalah peta Kecamatan Birem Bayeun (peta administrasi, peta jenis tanah, peta lereng dan peta penggunaan lahan) serta beberapa jenis bahan kimia untuk identifikasi tanah di lapangan seperti $\mathrm{H}_{2} \mathrm{O} 10 \%$, dan $30 \%, \mathrm{HCl} 10 \mathrm{~N}$, dan bahan-bahan kimia lainnya untuk analisis kimia tanah di laboratorium.

Alat yang digunakan adalah $\mathrm{pH}$ tancap, bor tanah, Global Positioning System (GPS), Sekop, Cangkul, alat tulis, printer, kamera digital dan seperangkat laptop yang telah terpasang software Microsoft Office 2007 dan ArcGIS 10.3.

Penelitian ini dilakukan dengan metode deskriptif yaitu dengan survey lahan dan pengambilan sampel tanah di lapangan serta hasil analisis sampel tanah di laboratorium. Diagaram Alir pelaksanaan penelitian disajikan pada Gambar 1.
Kegiatan pengumpulan data dan pengambilan contoh lapang terdiri dari data sumber daya lahan maupun produksi tanaman. Data yang dikumpulkan berupa data sekunder dan data primer yang berasal dari pengamatan langsung di lapangan. Dalam kegiatan lapang selanjutnya dilakukan pengamatan kenampakan morfologi tanah dan pengambilan sampel tanah pada kedalaman 30 dan 60. Untuk analisis sifat fisika dan kimia tanah di Laboratorium disajikan pada Tabel 2.

\section{Data Sumberdaya Lahan}

Kegiatan lapang dilakukan pengamatan dan pengambilan sampel tanah. Observasi dilakukan dengan menjelajahi seluruh areal sampel penelitian, kemudian menentukan dan membatasi satuan sampel pengamatan. Pengambilan contoh setiap satuan lereng diusahakan memiliki pewakil. Banyaknya faktor pembentuk satuan lahan yang diperoleh disesuaikan dengan keragaman lokasi. Pengambilan contoh tanah berdasarkan perbedaan fisiografi lahan yang diambil masing-masing 3 contoh tanah setiap unit lahan.

\section{Pengumpulan Data dan Pengambilan Contoh Lapang}

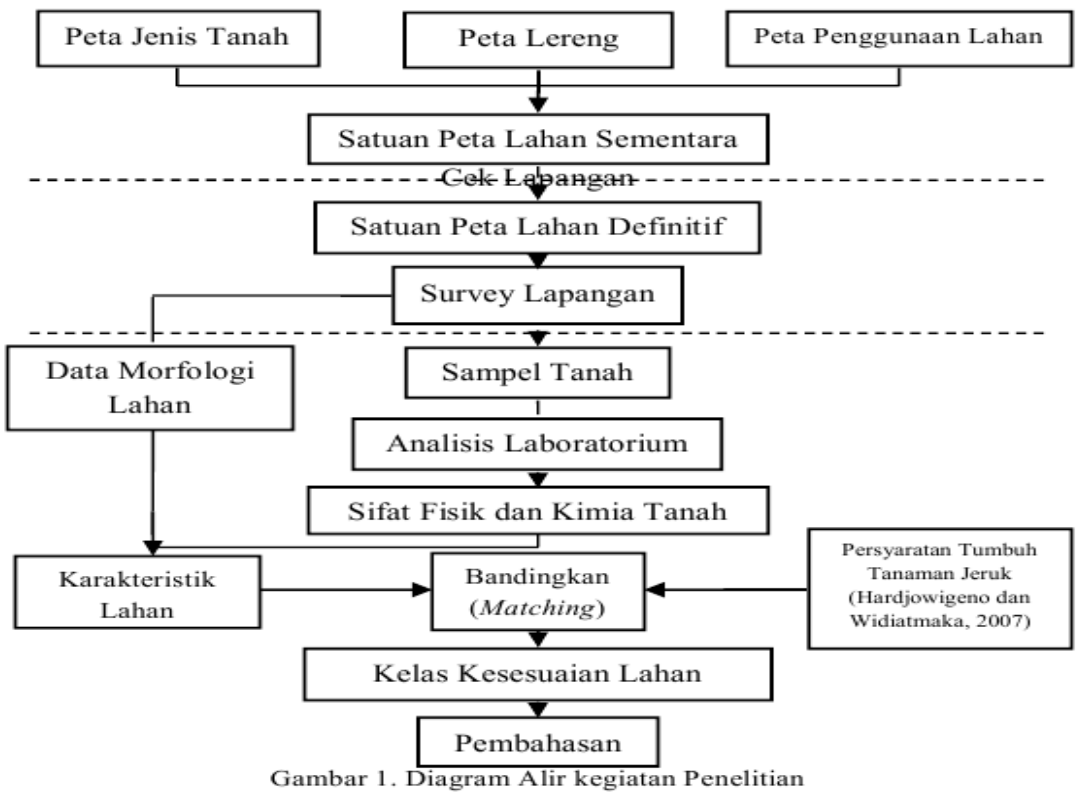


Tabel 2. Sifat Fisika dan Kimia yang dianalisis di Laboratorium.

\begin{tabular}{|c|c|c|c|c|}
\hline No & Parameter & Satuan & \multicolumn{2}{|l|}{ Metode analisis } \\
\hline & A. Fisika Tanah & & & \\
\hline \multirow[t]{2}{*}{1} & Tekstur tanah (3 Fraksi) & $\%$ & Pipet, Hukum stokes & \\
\hline & B. Kimia Tanah & & & \\
\hline 1 & $\mathrm{pH}$ & - & Elektrometrik & \\
\hline 2 & C-Organik & $\%$ & Walky \& Black & \\
\hline 3 & N-Total & $\%$ & Kjedahl & \\
\hline 4 & P-Total & $\%$ & Ektraksi dengan HCL 5\% & \\
\hline 5 & P-Tersedia & ppm & Bray II & \\
\hline \multirow[t]{6}{*}{6} & K-Total & ppm & Ektraksi dengan $\mathrm{NH} 4 \mathrm{OaC} \mathrm{pH} 7$ & \\
\hline & Kation- kation dapat ditukar & & & \\
\hline & K-dd & $\mathrm{me} / 100 \mathrm{~kg}$ & Ektraksi dengan $\mathrm{NH} 4 \mathrm{OaC} \mathrm{pH} 7$ & \\
\hline & Ca-dd & $\mathrm{me} / 100 \mathrm{~kg}$ & Ektraksi dengan $\mathrm{NH} 4 \mathrm{OaC} \mathrm{pH} 7$ & \\
\hline & Mg-dd & $\mathrm{me} / 100 \mathrm{~kg}$ & Ektraksi dengan $\mathrm{NH} 4 \mathrm{OaC} \mathrm{pH} 7$ & \\
\hline & $\mathrm{Na}-\mathrm{dd}$ & $\mathrm{me} / 100 \mathrm{~kg}$ & Ektraksi dengan $\mathrm{NH} 4 \mathrm{OaC} \mathrm{pH} 7$ & \\
\hline 8 & KTK & $\mathrm{me} / 100 \mathrm{~kg}$ & Ektraksi dengan $\mathrm{NH} 4 \mathrm{OaC} \mathrm{pH} 7$ & \\
\hline \multirow[t]{2}{*}{9} & Kejenuhan Basa & $\%$ & Jumlah Kation-kation Basa & \\
\hline & & & KTK & $\begin{array}{c}\text { x } 100 \% \\
\text { X }\end{array}$ \\
\hline 10 & Salinitas & Ms & Elektrika Conduktivity & \\
\hline
\end{tabular}

\section{HASIL DAN PEMBAHASAN Satuan Peta Lahan (SPL)}

Berdasarkan jenis tanah daerah penelitian ini dapat dibagi menjadi dua jenis tanah yaitu tanah Ultisol 472,86 $\mathrm{Ha}$ $(58,52 \%)$ dan Inceptisol 335,09 Ha. Dilihat dari kemiringan lahan, maka daerah penelitian kelas lereng dapat dikelompokkan kedalam tiga katagori yaitu : $0-3 \%$ seluas 318,01 Ha $(39,36 \%)$ dengan bentuk wilayah dataran-landai, 3-8\% seluas 460,15 $\mathrm{Ha}$ $(56,93 \%)$ dengan bentuk wilayah berombak dan $8-15 \%$ seluas $29,79 \mathrm{Ha}(3,69 \%)$ dengan bentuk wilayah bergelombang. Lokasi penelitian terdapat tiga macam bentuk penggunaan lahan daerah penelitian yang terdiri dari: ladang $453,69 \mathrm{Ha}(56,15 \%)$, sawah 237,95 Ha $(29,45 \%)$ dan semak belukar 116,32 Ha $(14,40 \%)$.

Satuan peta lahan dibentuk dengan jalan meng overlay tiga macam peta yaitu peta jenis tanah, peta lereng dan peta penggunaan lahan menjadi 7 Satuan Peta Lahan (SPL). Kemudian disetiap SPL diambil sampel tanah dianalisa di laboratorium untuk mengetahui sifat-sifat fisika dan kimianya. Selanjutnya data hasil analisa itu dikombinasikan dengan data skunder, yaitu curah hujan, temperatur ratarata tahunan dan bulan kering. Setiap jenis data tersebut dibandingkan dengan kriteria Hardjowigeno dan Widiatmaka (2007).

Ikhtisar tentangjenis tanah, klasifikasi lereng dan jenis penggunaan tanahnya seperti yang disajikan pada Tabel 3.

\section{Iklim}

Rata-rata curah hujan tahunan sebesar $2.490,2 \mathrm{~mm} / \mathrm{thn}$, dengan rata-rata bulan basah adalah 8,1 bulan, rata-rata bulan lembab yaitu 2,5 bulan dan rata-rata jumlah bulan kering adalah 1,4 bulan. Hasil analisis klasifikasi ikllim menurut SchmidtFergusson tipe iklim lokasi penelitian merupakan tipe B yaitu basah dengan curah hujan 2.490,2mm/tahun. Adapun rata-rata suhu tahunan di lokasi penelitian dari mulai $25-26{ }^{0} \mathrm{C}$.

\section{Sifat Fisika dan Kimia Tanah}

Sifat fisika tanah yang berpengaruh terhadap pertumbuhan dan perkembangan tanaman dilokasi studi pada kedalaman 30 dan $60 \mathrm{~cm}$ disajikan pada Tabel 4 . 
Tabel 3. Satuan Peta Lahan (SPL) Penelitian di Lokasi Penelitian

\begin{tabular}{|c|c|c|c|c|c|c|}
\hline \multirow{2}{*}{ SPL } & Jenis & Lereng & \multirow{2}{*}{ Relief } & Penggunaan & \multicolumn{2}{|c|}{ Luas } \\
\hline & Tanah & $(\%)$ & & Lahan & $\mathrm{Ha}$ & $\%$ \\
\hline 1 & Inceptisol & $8-15$ & Bergelombang & Ladang & 7,53 & 0,93 \\
\hline 2 & Ultisol & $0-3$ & Datar & Semak Belukar & 80,06 & 9,91 \\
\hline 3 & Ultisol & $8-15$ & Bergelombang & Ladang & 22,26 & 2,76 \\
\hline 4 & Inceptisol & $0-3$ & Datar & Sawah & 237,95 & 29,45 \\
\hline 5 & Ultisol & $3-8$ & Berombak & Ladang & 334,28 & 41,37 \\
\hline 6 & Untisol & $3-8$ & Berombak & Semak Belukar & 36,26 & 4,49 \\
\hline 7 & Inceptisol & $3-8$ & Berombak & Ladang & 89,62 & 11,09 \\
\hline \multicolumn{5}{|c|}{ Total } & 807,95 & 100 \\
\hline
\end{tabular}

Sumber : Data diolah, 2018

Tabel 4. Sifat-sifat fisika tanah dilokasi penelitian pada kedalaman 30 dan $60 \mathrm{~cm}$

\begin{tabular}{|c|c|c|c|}
\hline No & Sifat Fisika & Keterangan & Lokasi (SPL) \\
\hline 1. & Kedalaman efektif & $>100 \mathrm{~cm}$ & Semua SPL \\
\hline \multirow[t]{9}{*}{2.} & Tekstur lapang & & \\
\hline & Kedalaman $30 \mathrm{~cm}$ & Lempung berdebu & 4 \\
\hline & & Lempung liat berpasir & 7 dan 6 \\
\hline & & Lempung berliat & 1 \\
\hline & & Lempung berpasir & 2 dan 3 \\
\hline & & Lempung & 5 \\
\hline & Kedalaman $60 \mathrm{~cm}$ & Lempung berliat & 1 dan 4 \\
\hline & & Lempung liat berpasir & 2,3 dan 5 \\
\hline & & Liat & 6 dan 7 \\
\hline \multirow[t]{2}{*}{3.} & Drainase & Buruk & 4 \\
\hline & & Baik & $1,2,3,5,6$ dan 7 \\
\hline 4. & Banjir/genangan & Tidak ada & Semua SPL \\
\hline 5. & Batuan di permukaan & Tidak ada & Semua SPL \\
\hline \multirow[t]{3}{*}{6.} & Lereng & $0-3$ & 4 dan 2 \\
\hline & & $3-8$ & 5,6 dan 7 \\
\hline & & $8-15$ & 1 dan 3 \\
\hline \multirow[t]{3}{*}{7.} & Bahaya Erosi & Sangat Rendah & 4 dan 2 \\
\hline & & Rendah & 5,6 dan 7 \\
\hline & & Sedang & 1 dan 3 \\
\hline
\end{tabular}

Sumber : Data diolah, 2018

\section{Sifat Kimia Tanah}

Beberapa sifat kimia tanah yang dijumpai laboratorium pada kedalaman 30 dan $60 \mathrm{~cm}$ dilokasi penelitian berdasarkan hasil analisis disajikan pada Tabel 5 dan 6 .

Tabel 5. Hasil Analisis Sifat Kimia Tanah pada Kedalaman $30 \mathrm{~cm}$ di Laboratorium

\begin{tabular}{|c|c|c|c|c|}
\hline No & Sifat Kimia Tanah & Hasil Analisis & Kriteria & Lokasi (SPL) \\
\hline 1. & $\mathrm{pH}(\mathrm{H} 2 \mathrm{O})$ & $4,91-5,26$ & $\mathrm{M}$ & Semua SPL \\
\hline 2. & C-Organik & $0,31-0,79$ & SR & Semua SPL \\
\hline \multirow[t]{2}{*}{3.} & N-Total & $0,04-0,09$ & SR & $1,2,3,5$ dan 6 \\
\hline & & $0,10-0,11$ & $\mathrm{R}$ & 4 dan 7 \\
\hline 4. & P-Bray-II & $0,05-2,10$ & SR & Semua SPL \\
\hline \multicolumn{5}{|c|}{ KT } \\
\hline \multirow{2}{*}{\multicolumn{2}{|c|}{$\mathrm{Ca}$}} & 0,92 & SR & 5 \\
\hline & & $1,94-3,55$ & $\mathrm{R}$ & $1,2,3,4,6$ dan 7 \\
\hline \multirow{2}{*}{\multicolumn{2}{|c|}{$\mathrm{Mg}$}} & $0,34-0,38$ & SR & 1,2,3 dan 6 \\
\hline & & $0,43-0,46$ & $\mathrm{R}$ & 4,5 dan 7 \\
\hline & \multirow[t]{3}{*}{$\mathrm{K}$} & $0,03-0,05$ & SR & 2,3 dan 6 \\
\hline & & $0,15-0,26$ & $\mathrm{R}$ & 4,5 dan 7 \\
\hline & & 0,40 & $S$ & 1 \\
\hline & \multirow[t]{2}{*}{$\mathrm{Na}$} & $0,03-0,09$ & SR & 1,3 dan 6 \\
\hline & & $0,12-0,21$ & $\mathrm{R}$ & $2,4,5$ dan 7 \\
\hline 6. & KTK & $8,00-12,80$ & $\mathrm{R}$ & $2,3,4,5,6$ dan 7 \\
\hline
\end{tabular}




\begin{tabular}{|c|c|c|c|}
\hline & $\begin{array}{l}22,00 \\
19,91\end{array}$ & $\begin{array}{c}S \\
S R\end{array}$ & 1 \\
\hline 7. & $\begin{array}{c}19,91 \\
21,38-39,30\end{array}$ & $\begin{array}{c}\text { SR } \\
\mathrm{R}\end{array}$ & $2,3,4,5,6$ dan 7 \\
\hline
\end{tabular}

Sumber : Data di olah,2018

Ket $: \mathrm{M}=$ Masam, $\mathrm{SR}=$ Sangat Rendah, $\mathrm{R}=$ Rendah, $\mathrm{S}=$ Sedang

Tabel 6. Hasil Analisis Sifat Kimia Tanah pada Kedalaman 60 cm di Laboratorium

\begin{tabular}{|c|c|c|c|c|}
\hline No & $\begin{array}{c}\text { Sifat Kimia } \\
\text { Tanah }\end{array}$ & Hasil Analisis & Kriteria & Lokasi (SPL) \\
\hline \multicolumn{2}{|c|}{$\begin{array}{ll}1 . & \mathrm{pH}(\mathrm{H} 2 \mathrm{O})\end{array}$} & $\begin{array}{c}4,58-5,25 \\
5,70\end{array}$ & $\begin{array}{l}\text { M } \\
\text { AM }\end{array}$ & $\begin{array}{c}1,2,3,5,6 \text { dan } 7 \\
4\end{array}$ \\
\hline & C-Organik & $0,18-0,50$ & SR & Semua SPL \\
\hline 3. & N-Total & $0,03-0,05$ & SR & Semua SPL \\
\hline \multicolumn{2}{|c|}{ 4. P-Bray-II } & $0,20-1,50$ & SR & Semua SPL \\
\hline \multicolumn{5}{|c|}{ 5. KT } \\
\hline & $\mathrm{Ca}$ & $3,01-3,77$ & $\mathrm{R}$ & Semua SPL \\
\hline & $\mathrm{Mg}$ & $0,18-0,39$ & SR & Semua SPL \\
\hline \multirow{2}{*}{\multicolumn{2}{|c|}{ K }} & $0,03-0,10$ & SR & $2,3,4$ dan 5 \\
\hline & & $0,15-0,25$ & $\mathrm{R}$ & 1,6 dan 7 \\
\hline \multirow{2}{*}{\multicolumn{2}{|c|}{$\mathrm{Na}$}} & $0,03-0,07$ & SR & $2,3,4,5,6$ dan 7 \\
\hline & & 0,11 & $\mathrm{R}$ & 1 \\
\hline \multirow{2}{*}{\multicolumn{2}{|c|}{ 6. KTK }} & $8,00-16,40$ & $\mathrm{R}$ & $2,3,4,5$ dan 6 \\
\hline & & $17,20-18,00$ & $\mathrm{~S}$ & 1 dan 7 \\
\hline \multirow{3}{*}{\multicolumn{2}{|c|}{ 7. $\mathrm{KB}$}} & 19,28 & SR & 1 \\
\hline & & $21,16-28,75$ & $\mathrm{R}$ & $4,5,6$ dan 7 \\
\hline & & $31,12-48,63$ & $\mathrm{~S}$ & 2 dan 3 \\
\hline
\end{tabular}

Sumber : Data diolah, 2018

\section{Kesesuaian Lahan Aktual}

Hasil analisis kesesuaian lahan SPL 1 sampai SPL 7. Hasil penilaian kesesuaian menunjukkan bahwa secara aktual dilokasi lahan aktual pada tingkat kelas dan sub kelas penelitian hanya mempunyai kelas kesesuaian dengan kedalaman 30 dan $60 \mathrm{~cm}$ disajikan pada

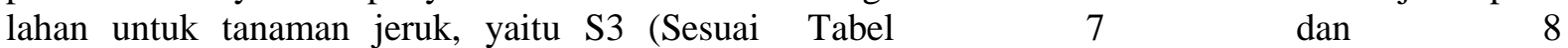
Marginal) seluas 807,95 Ha yang meliputi areal

Tabel 7. Hasil penilaian kesesuaian lahan aktual pada kedalaman $30 \mathrm{~cm}$

\begin{tabular}{|c|c|c|c|c|c|c|}
\hline \multirow[b]{2}{*}{ No } & \multirow[b]{2}{*}{ SPL } & \multicolumn{2}{|c|}{ Kelas Kesesuaian Lahan } & \multirow[b]{2}{*}{ Faktor Pembatas } & \multicolumn{2}{|c|}{ Luas } \\
\hline & & Kelas & Sub Kelas & & Ha & $\%$ \\
\hline 1. & 1 & S3 & S3fne & $\begin{array}{c}\text { Retensi hara, Hara } \\
\text { tersedia, Bahaya } \\
\text { erosi }\end{array}$ & 7,53 & 0,93 \\
\hline 2. & 2 & S3 & S3rfn & $\begin{array}{c}\text { Media perakaran, } \\
\text { Retensi hara, Hara } \\
\text { tersedia }\end{array}$ & 80,06 & 9,91 \\
\hline 3. & 3 & S3 & S3rne & $\begin{array}{c}\text { Media perakaran, } \\
\text { Hara tersedia, } \\
\text { Bahaya erosi }\end{array}$ & 22,26 & 2,76 \\
\hline 4. & 4 & S3 & S3rn & $\begin{array}{l}\text { Media perakaran, } \\
\text { Hara tersedia }\end{array}$ & 237,95 & 29,45 \\
\hline 5. & $5,6,7$ & S3 & $\mathrm{S} 3 \mathrm{n}$ & Hara tersedia & 460,16 & 56,95 \\
\hline & & & otal & & $\mathbf{8 0 7 , 9 5}$ & 100,00 \\
\hline
\end{tabular}

Sumber : Data di olah, 2018

Keterangan : $\mathrm{r}=$ Media Perakaran, $\mathrm{f}=$ Retensi Hara, $\mathrm{n}=$ Ketersediaan Hara, $\mathrm{e}=$ Tingkat Bahaya Erosi 
Tabel 8. Hasil penilaian kesesuaian lahan aktual pada kedalaman $60 \mathrm{~cm}$

\begin{tabular}{|c|c|c|c|c|c|c|}
\hline \multirow{2}{*}{ No } & \multirow{2}{*}{ SPL } & \multicolumn{2}{|c|}{ Kelas Kesesuaian Lahan } & \multirow{2}{*}{ Faktor Pembatas } & \multicolumn{2}{|c|}{ Luas } \\
\hline & & Kelas & Sub Kelas & & $\mathrm{Ha}$ & or \\
\hline 1. & 1 & S3 & S3fne & $\begin{array}{c}\text { Retensi hara, Hara } \\
\text { tersedia, Bahaya } \\
\text { erosi }\end{array}$ & 7,53 & 0,93 \\
\hline 2. & 2 & S3 & S3fn & $\begin{array}{l}\text { Retensi hara, Hara } \\
\text { tersedia }\end{array}$ & 80,06 & 9,91 \\
\hline 3. & 3 & S3 & S3ne & $\begin{array}{l}\text { Hara tersedia, } \\
\text { Bahaya erosi }\end{array}$ & 22,26 & 2,76 \\
\hline 4. & $4,6,7$ & S3 & S3rn & $\begin{array}{c}\text { Media perakaran, } \\
\text { Hara tersedia }\end{array}$ & 661,85 & 81,91 \\
\hline \multirow[t]{2}{*}{5.} & 5 & S3 & S3n & Hara tersedia & 36,26 & 4,49 \\
\hline & & & Total & & 807,95 & 100,00 \\
\hline
\end{tabular}

Faktor pembatas S3 yang terdapat dilokasi penelitian dengan media perakaran (tekstur) terdapat pada SPL 2 dan 3 dengan kedalaman 30 $\mathrm{cm}$ dan kedalaman $60 \mathrm{~cm}$ pada SPL 6 dan 7 dan (drainase) terdapat pada SPL 4 dengan kedalaman 30 dan $60 \mathrm{~cm}$, retensi hara $(\mathrm{pH}$ tanah) pada SPL 1 dan 2 pada kedalaman 30 dan $60 \mathrm{~cm}$, hara tersedia (total-N) pada SPL 1,2,3,5 dan 6 dengan kedalaman 30 dan kedalaman 60 cmpada semua SPL, ( $\left.\mathrm{P}_{2} \mathrm{O}_{5}\right)$ pada semua SPL dengan kedalaman $30 \mathrm{~cm}$ dan $60 \mathrm{~cm}$ dan tingkat bahaya erosi (bahaya erosi dan lereng) pada SPL 1 dan 3 dengan kedalaman 30 dan $60 \mathrm{~cm}$.

\section{Kesesuaian Lahan Potensial}

Kelas kesesuaian lahan potensial dapat ditingkatkan kelas kesuaiannya dengan cara memberi input teknologi untuk menanggulangi faktor pembatas yang ada. Tingkat teknologi yang diberikan adalah dalam bentuk High Input (HI).

Usaha perbaikan lahan di lokasi penelitian berdasarkan dari faktor-faktor pembatas yang ada pada masing-masing satuan lahan. Hal ini bertujuan untuk meningkatkan produktivitas tanah dan hasil tanaman jeruk setelah dilakukan beberapa usaha perbaikan akan didapatkan tingkat kesesuaian lahan potensial. Kesesuaian lahan aktual dan kesesuaian lahan potensial di lokasi penelitian pada kedalaman 30 dan $60 \mathrm{~cm}$ disajikan pada Tabel 9 dan 10.

Berdasarkan Tabel 9 dan 10 pada lokasi penelitian kelas kesesuaian lahannya adalah S3. Faktor pembatas yang paling dominan adalah hara tersedia yaitu total $\mathrm{N}$ masih bisa diatasi dengan cara memberikan pupuk yang mengandung unsur N pada tanaman. Menurut Isrun (2009) salah satu upaya untuk meningkatkan unsur hara $\mathrm{N}$ dalam tanah yaitu dengan pemberian bahan organik berupa pupuk cair organik dapat memperbaiki sifat kimia ketersediaan $\mathrm{N}$ dan $\mathrm{P}_{2} \mathrm{O}_{5}$ dapat mengikuti rekomendasi Balai Penelitian Jeruk dan Buah Subtropika (Balitjestro), 2014 disajikan pada Tabel 11.

Tabel 9. Kesesuaian Lahan Aktual dan Kesesuaian Lahan Potensial di Lokasi Penelitian pada Kedalaman

\begin{tabular}{|c|c|c|c|c|c|c|}
\hline \multirow{2}{*}{$\begin{array}{l}\text { No } \\
\text { SPL }\end{array}$} & \multirow{2}{*}{$\begin{array}{c}\text { Kesesuaian } \\
\text { Lahan } \\
\text { Aktual } \\
\end{array}$} & \multirow{2}{*}{ Usaha Perbaikan } & \multirow{2}{*}{$\begin{array}{c}\text { Tingkat } \\
\text { Teknologi }\end{array}$} & \multirow{2}{*}{$\begin{array}{c}\text { Kesesuaian } \\
\text { Lahan } \\
\text { Potensial } \\
\end{array}$} & \multicolumn{2}{|c|}{ Luas } \\
\hline & & & & & Ha & $\%$ \\
\hline 1 & S3fne & $\begin{array}{l}\text { Kapur+Pemupukan } \\
\text { +Konservasi } \\
\text { vegetatif }\end{array}$ & +++ & $\mathrm{S} 1$ & 7,53 & 0,93 \\
\hline 2 & S3rfn & Kapur+pemupukan & +++ & S3r & 80,06 & 9,91 \\
\hline 3 & S3rne & $\begin{array}{l}\text { Pemupukan+ } \\
\text { Konservasi } \\
\text { vegetatif }\end{array}$ & +++ & $\mathrm{S} 3 \mathrm{r}$ & 22,26 & 2,76 \\
\hline 4 & S3rn & $\begin{array}{l}\text { Drainase+ } \\
\text { Pemupukan }\end{array}$ & +++ & $\mathrm{S} 1$ & 237,95 & 29,45 \\
\hline
\end{tabular}




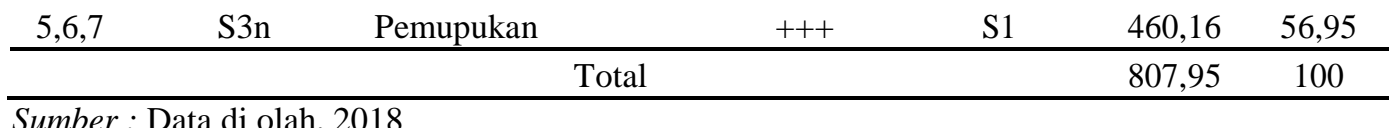

Keterangan : +++ : Tingkat teknologi tinggi

Tabel 10. Kesesuaian Lahan Aktual dan Kesesuaian Lahan Potensial di Lokasi Penelitian pada Kedalaman $60 \mathrm{~cm}$.

\begin{tabular}{|c|c|c|c|c|c|c|}
\hline \multirow{2}{*}{$\begin{array}{l}\text { No } \\
\text { SPL }\end{array}$} & \multirow{2}{*}{$\begin{array}{c}\text { Kesesuaian } \\
\text { Lahan } \\
\text { Aktual }\end{array}$} & \multirow{2}{*}{$\begin{array}{c}\text { Usaha } \\
\text { Perbaikan }\end{array}$} & \multirow{2}{*}{$\begin{array}{c}\text { Tingkat } \\
\text { Teknologi }\end{array}$} & \multirow{2}{*}{$\begin{array}{c}\text { Kesesuaian } \\
\text { Lahan } \\
\text { Potensial }\end{array}$} & \multicolumn{2}{|c|}{ Luas } \\
\hline & & & & & Ha & $\%$ \\
\hline 1 & S3fne & $\begin{array}{l}\text { Kapur } \\
+ \text { Pemupukan } \\
+ \text { Konservasi } \\
\text { vegetatif }\end{array}$ & +++ & $\mathrm{S} 1$ & 7,53 & 0,93 \\
\hline 2 & S3fn & $\begin{array}{l}\text { Kapur+ } \\
\text { pemupukan }\end{array}$ & +++ & S1 & 80,06 & 9,91 \\
\hline 3 & S3ne & $\begin{array}{l}\text { Pemupukan+ } \\
\text { Konservasi } \\
\text { vegetatif }\end{array}$ & +++ & S1 & 22,26 & 2,76 \\
\hline $4,6,7$ & S3rn & $\begin{array}{l}\text { Drainase+ } \\
\text { Pemupukan }\end{array}$ & +++ & S3r & 363,82 & 45,03 \\
\hline 5 & S3n & Pemupukan & +++ & $\mathrm{S} 1$ & 334,28 & 41,37 \\
\hline & & Total & & & 807,95 & 100 \\
\hline
\end{tabular}

Sumber : Data di olah, 2018

Faktor pembatas media perakaran berupa tekstur tanah dan drainase. Tekstur tanah bersifat permanen sehingga tidak dapat diperbaiki, hal ini dikarenakan tekstur tanah tidak akan berubah pada waktu yang lama, contohnya tekstur pasir sulit dirubah menjadi lempung atau tekstur liat sulit dirubah menjadi pasir, menurut Hardjowigeno dan Widiatmaka (2007) dalam evaluasi kesesuaian lahan dengan faktor media perakaran berupa tekstur tidak dapat dilakukan perbaikan, sedangkan drainase dapat dilakukan perbaikan dengan pembuatan saluran drainase.

Upaya perbaikan $\mathrm{pH}$ dengan cara pemberian kapur, hal ini didukung dengan Hardjowigeno (2003) yang menyatakan untuk mengubah $\mathrm{pH}$ tanah yang masam dengan menambahkan kapur kedalam tanah. Pengapuran didalam tanah dapat memperbaiki sifat fisik, kimia dan biologi tanah.

Lokasi penelitian mempunyai tingkat bahaya erosi dengan kelerengan $8-15 \%$ dapat diatasi dengan penanaman kacang hias (Arachis pintoi) yang merupakan salah satu spesies anggota dari family Leguminosae atau kacangkacangan selain Colopogonium mucunoides, Capsicum pubescens, Mucuna bracteata secara umum. Menurut Maswar (2004) kacang hias dapat menekan erosi $11-85 \%$. Selain itu peneliti juga melaporkan bahwa kacang hias efektif menekan gulma dan penggunaan herbisida dan bahkan memiliki keunggulan lain sebagai alternatif baru untuk tanaman hias dan sebagai sumber nektar yang baik untuk lebah.

Tabel 14. Rekomendasi umum pemupukan Balitjestro

\begin{tabular}{ccc}
\hline $\begin{array}{c}\text { Umur } \\
\text { (tahun) }\end{array}$ & P2O5 (gr/pohon) & Aplikasi \\
\hline $0-1$ & 10 & $3-4 \mathrm{kali}$ \\
$1-2$ & 10 & $3-4 \mathrm{kali}$ \\
$2-3$ & $10-30$ & $3-4 \mathrm{kali}$ \\
$3-4$ & $30-50$ & $2-3 \mathrm{kali}$ \\
$4-5$ & $50-80$ & $2 \mathrm{kali}$ \\
$>5$ & 04\% dari 2\% bobot panen & $2 \mathrm{kali}$ \\
\hline \multicolumn{2}{l}{ Sumber: Balai Penelitian Jeruk dan Buah Subtropika (Balitjestro), 2014 }
\end{tabular}




\section{KESIMPULAN DAN SARAN}

\section{Kesimpulan}

1.Berdasarkan hasil evaluasi kesesuaian lahan dilokasi penelitian menunjukan bahwa lahan tersebut sesuai untuk pengembangan tanaman jeruk tetapi dapat terlihat media perakaran, retensi hara, hara tersedia dan tingkat bahaya erosi sebagai faktor pembatas/S3 (sesuai marginal) dapat diperbaiki menjadi S1 (sangat sesuai).

2. Karakteristik lahan S3 untuk pengembangan tanaman jeruk di Desa Jambo Labu Kecamatan Birem Bayeun dapat memberikan input perbaikan untuk kesesuian lahan agar dapat dinaikan kelas kesesuaiannya menjadi S1 (sangat sesuai). Upaya perbaikan media

\section{DAFTAR PUSTAKA}

Balitjestro. 2014. Nilai Kelayakan Ekonomi Usaha Tani Jeruk Siam. http://balitjestro.litbang.pertanian.go.id/nil -kelayakan-ekonomiusahatanijeruksiam/(diakses, 15 April 2018).

Hardjowigeno, S. 2003. Klasifikasi Tanah dan Pedogenesis. Jakarta : Akademika Pressindo. 250 hal.

Hardjowigeno, S., Widiatmaka. 2007. Evaluasi Kesesuaian Lahan dan Perencanaan Tataguna Lahan. Yogyakarta (ID): Gadjah Mada University Press.

Isrun. 2009, Analisis Tingkat Kerusakan Lahan Pada Beberapa Sub DAS di Kawasan Danau Poso, Media Litbang, Sulawesi Tenggara.

Kementerian Pertanian. 2016. Pusat Data dan Sistem Informasi Pertanian. Jakarta. Kementerian Pertanian.

Maswar. 2004. Kacang hias (Arachis pintoi) pada usaha tani lahan kering. perakaran dengan pembuatan saluran drainase, retensi hara $(\mathrm{pH}$ tanah) dengan pengapuran, hara tersedia (total $\mathrm{N}$ dan $\mathrm{P}_{2} \mathrm{O}_{5}$ ) dengan pemberian pupuk yang mengandung unsur Nitrogen/pupuk organik dan pupuk yang mengandung unsur fosfor dan tingkat bahaya erosi (bahaya erosi dan lereng) 8-15\% dengan cara konservasi vegetatif.

\section{Saran}

Hasil penelitian ini dapat dilanjutkan dengan percobaan dilapangan dengan melakukan penanaman jeruk dengan perlakuan penambahan pupuk yang mengandung unsur $\mathrm{P}$ dan $\mathrm{N}$, penanaman kacang hias (Arachis pintoi) pada lereng $8-15 \%$.

Balai Penelitian Tanah [Internet]. [diunduh 4 Desember 2018]. http//:balittanah.litbang.deptan.go.id/indek s.pht?option=com_content $\&$ view $=$ article $\&$ id=43: kacang-hias

arachispintoi\&catid=23:leaflet $\&$ ltemid $=91$

Pusat data dan Sistem Informasi Pertanian. 2015. Statistisk Pertanian. Kementrian Pertanian Republik Indonesia, Jakarta.

Ritung S., Wahyunto, Agus F dan Hidayat H. 2007. Panduan Evaluasi Kesesuaian Lahan. Balai Penelitian Tanah Bogor.

Sitorus, 2004. Survai Tanah dan Penggunaan Lahan. Bogor (ID): Lab Perencanaan Pengembangan Sumberdaya Lahan, Jurusan Tanah, Fakultas Pertanian, Institut Pertanian Bogor. 